\title{
Diabetikerin unterkühlt vor dem heimischen Kühlschrank
}

\author{
Eine ältere Dame mit langjährigem Typ-1-Diabetes wird deutlich unterkühlt in ihrer geheizten \\ Wohnung gefunden. Nach der Fahrt in die Rettungsstelle eines großen Krankenhauses wird \\ noch eine Körperkerntemperatur von 32 Grad Celsius gemessen. Wie konnte es dazu kommen?
}

Eine 1939 geborene Frau erkrankte 1969 an einem Typ-1-Diabetes-mellitus. Jahrzehnte später entwickelte sie multiple diabetische Sekundärkomplikationen. So hat sie etwa eine schwere periphere Polyneuropathie. Als Folge eines Charcot-Fußes links fühlt sich die Patientin beim Gehen unsicher. Aufgrund einer diabetischen Nephropathie besteht bei ihr eine chronische Niereninsuffizienz mit einer GFR von $39 \mathrm{ml} / \mathrm{min}$. In den letzten Jahren hat sich außerdem eine Hypoglykämie-Wahrnehmungsstörung entwickelt, die bei Unterzuckerungen zu plötzlichen Bewusstseinseinschränkungen ohne vegetative Warn-Symptoma-

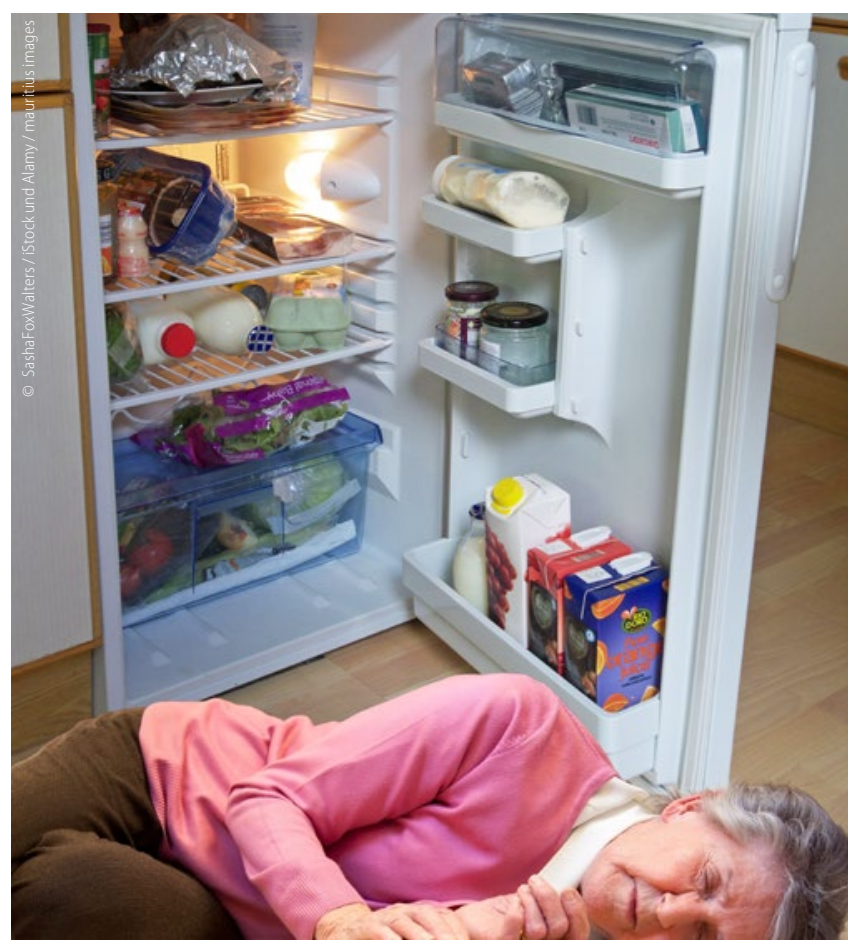

Fabula docet:

Bei Menschen mit Langzeit-Diabetes und ausgeprägtem Spätsyndrom besteht häufig eine hohe Motivation, durch eine straffe Stoffwechseleinstellung ein weiteres Fortschreiten der oft zu einem deutlichen Verlust an Lebensqualität führenden Sekundärkomplikationen zu verzögern. Gerade bei Hypoglykämie-Wahrnehmungsstörungen kann dies zu gefährlichen Situationen führen. Eine Unterkühlung vor dem Kühlschrank ist sicher ein Kuriosum. Im Winter im Freien sind solche Unfälle aber gar nicht so ungewöhnlich. tik führt. Es war schon mehrmals Fremdhilfe bei Hypoglykämien notwendig.

Wegen einer Netzhautblutung bei diabetischer Retinopathie erblindete die Patientin 2004 trotz Operation auf dem linken Auge. Aus Angst, durch eine progrediente Retinopathie auch auf dem rechten Auge zu erblinden, spritzt sie im Rahmen ihrer intensivierten Insulintherapie eher etwas mehr Insulin als mit dem ambulanten Diabetologen besprochen, um keine erhöhten Blutzuckerwerte zu riskieren.

\section{Das Abendbrot war in Planung}

Im November vergangenen Jahres kam es dann zu folgender Situation, wie sie später berichtete: Sie bereitete in der Küche ihr Abendbrot vor. Sie hatte Hunger, wollte daher etwas mehr essen als sonst, und spritzte deshalb eine erhöhte Dosis ihres schnell wirkenden Insulinanalogons.

Kurz darauf hatte sie das Gefühl einer drohenden Hypoglykämie und öffnete den Kühlschrank, um sich etwas zu Essen heraus zu nehmen. Vor dem geöffneten Kühlschrank bricht sie bewusstlos zusammen. Erst nach mehreren Stunden fanden aufmerksame Nachbarn die inzwischen unterkühlte Frau auf dem Fußboden vor dem geöffneten Kühlschrank liegend auf. Der Notarzt maß einen Blutzucker von $44 \mathrm{mg} / \mathrm{dl}$ und therapierte mit einer intravenösen Glukoseinfusion. Trotz Aufwärmmaßnahmen durch das Rettungsteam im Notarztwagen musste bei der Einlieferung in die Rettungsstelle noch eine Hypothermie von 32 Grad Körperkerntemperatur diagnostiziert werden.

\section{Schulung und BE-Anpassung als Konsequenz}

Nach Begleitung des Temperaturausgleichs auf der Überwachungsstation wurde sie auf eine Diabetesstation verlegt. Dort erhielt sie eine spezielle Hypoglykämie-Schulung und eine Anpassung der BE-Faktoren, um die Wahrscheinlichkeit für zukünftige schwere Hypoglykämien zumindest zu reduzieren.

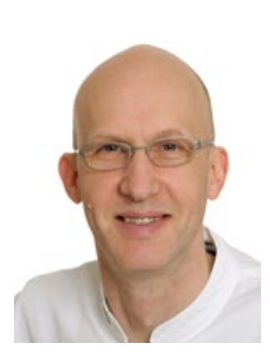

Dipl.-Med. Christoph Hartwig

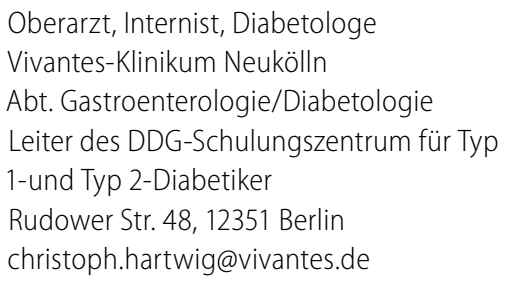

Oberarzt, Internist, Diabetologe

Vivantes-Klinikum Neukölln

Abt. Gastroenterologie/Diabetologie

Leiter des DDG-Schulungszentrum für Typ

1-und Typ 2-Diabetiker

christoph.hartwig@vivantes.de 